\title{
Muscle pathology, thymoma, and immunological abnormalities in patients with myasthenia gravis
}

\author{
H. J. G. H. OOSTERHUis, J. BETHLEM, AND T. E. W. FELTKAMP \\ From the Neurological Clinic, Wilhelmina Gasthuis, and the Central Laboratory of the Netherlands Red Cross \\ Blood Transfusion Service, and Laboratory of Immunopathology, \\ University of Amsterdam, The Netherlands
}

In 1901, Weigert described a patient with myasthenia gravis, thymoma, and lymphorrhages. He regarded these lymphocellular infiltrates in the muscles as metastases of the thymoma. Lymphorrhages have since been frequently described in patients with myasthenia, with or without thymoma (Link, 1903; Rowland, Hoefer, Aranow, and Houston Merritt, 1956; Mendelow, 1958; Genkins, Mendelow, Sobel, and Osserman, 1961). Fenichel and Shy (1963), Fenichel (1966), and Engel and McFarlin (1966) likewise mentioned the presence of lymphorrhages in muscle biopsies, but unrelated to the presence of a thymoma. In our own material (Oosterhuis 1963, 1964) a correlation between the presence of a thymoma and the lymphocellular infiltrations could be demonstrated.

Antibodies against muscular tissue have been demonstrated in $30-40 \%$ of patients with myasthenia gravis, and in $95-100 \%$ of myasthenic patients with a thymoma (Van der Geld, Feltkamp, Loghem, Oosterhuis, and Biemond, 1963; Strauss, 1966; Oosterhuis, Van der Geld, and Feltkamp, 1967).

This finding supported the assumption that myasthenia gravis might be included among the autoimmune diseases. In all idiopathic autoimmune diseases, lymphocellular infiltrates are found in the affected organs. The presence of such infiltrates in the muscles of patients with myasthenia gravis suggests that the muscle is involved in or the target of cellular immune reaction, in which circulating antibodies against muscular tissue might be of secondary importance. Besides lymphocellular infiltrates, other abnormalities have been described in the muscles of patients with myasthenia-for example, neurogenic muscular atrophy (Russell, 1953; Fenichel and Shy, 1963; Fenichel, 1966; Engel and McFarlin, 1966) and focal myositis (Russell, 1953; Genkins et al., 1961). The latter abnormality seems to occur chiefly in patients with a thymoma (Genkins et al., 1961). The neurogenic abnormalities, however, are believed not to correlate with the presence of a thymoma (Fenichel and Shy, $\stackrel{\mathbb{\Omega}}{\circ}$ 1963).

The purpose of the present study was to establish $\vec{\circ}$ whether some of the muscular changes most commonly found in patients with myasthenia- $\vec{\omega}$ lymphorrhages, neurogenic changes, and focal myositis - correlate with the presence of a thymoma and/or the presence of circulating antibodies against muscular tissue or nuclei (A.N.F.).

\section{MATERIAL AND METHODS}

HISTOLOGY Quadriceps muscle was examined hist logically in 30 patients with generalized myasthen gravis. In 26 this was done by a biopsy and in four patien at necropsy. In nine patients, one or more muscles were $\frac{+}{+}$ examined by biopsy (three patients) or at necropsy (s patients) in addition to the quadriceps muscle. An analyse of the histological pictures of these muscles led us $\overrightarrow{0}$ conclude that the quadriceps muscle was representative $ᄋ$ for the other muscles examined in these patients. Of each muscle at least two transverse and two longitudinal sections were examined after haematoxylin-eosin and Gomori's trichrome staining.

We defined lymphorrhage as an accumulation of mononuclear cells; these lymphocellular infiltrates were $\mathbb{D}$ not always situated perivascularly.

Neurogenic muscular atrophy was defined as the $\overrightarrow{\overrightarrow{0}}$ presence of large groups of small, usually polygonal 3 muscle fibres, sometimes associated with: (1) a relative increase in small hyperchromatic nuclei; (2) an increase in endomysial connective tissue; (3) the presence of target fibres.

Focal myositis was defined as the focal occurrence of marked structural changes in the muscle fibres associated with an inflammatory infiltrate.

THYMOMA

The presence of a thymoma was diagnosed in 15 patients in the following ways: histological examination of the $\frac{1}{0}$ tumour after operation or at necropsy in nine patients; histological examination of a needle biopsy of the tumour $\mathrm{N}$ in two patients; radiograph of a lobulated mass in the anterior mediastinum in four patients. 
A thymoma was ruled out in 15 patients by means of: (1) negative findings at operation or necropsy in five patients; (2) negative plain radiograph findings after a duration of illness of at least seven years in seven patients; (3) negative tomograms of the anterior mediastinum in three planes in two patients; (4) negative plain radiographic findings after one year of illness in one patient.

In 11 patients the thymoma was present at the moment of the muscle biopsy; in four patients a thymoma had been removed two, two, four, and six years previously, respectively.

IMMUNOLOGY Antibodies to skeletal muscle alternating striations were determined with the indirect immunofluorescent technique in sera diluted $1: 10$, according to the method described previously (Feltkamp and van Rossum, 1968). Antibodies to nuclei (A.N.F.) were determined with adrenocortex as substrate, as described before (Feltkamp and van Rossum, 1968). Rat liver was also used as nuclear substrate. The same method was used for this, with the exception that undiluted serum was used and that the washings were performed at room temperature with barbitone buffered saline (Na-barbitone 2.06 gr.; $\mathrm{NaCl} 8.5 \mathrm{gr}$.; $\mathrm{HCl} 0.1 \mathrm{~N} 80.6 \mathrm{ml}$.; aqua dest. ad $1,000 \mathrm{ml}$.) of $p H 7 \cdot 2$. For all three immunofluorescent tests the IgG fraction from rabbit anti-human immunoglobulin, conjugated to fluorescein isothiocyanate as described by The and Feltkamp (1968), was used. The characteristics of the final product were: IgG concentration $2 \mathrm{mg} / \mathrm{ml}$; molecular $\mathrm{F} / \mathrm{P}$ ratio $2 \cdot 1$; agar bloctitration titre against human IgG $1: 8$ (The and Feltkamp, 1968); final dilution used 1:20.

PATIENTS The investigations were carried out in 30 patients. Some data on these patients are given in Table I. The chi-square test was used in statistical analysis.

\section{TABLE I}

TYPE OF MYASTHENIA, AGE, SEX, AND PRESENCE OF A THYMOMA IN 30 PATIENTS

\begin{tabular}{lcc} 
& Thymoma & $\begin{array}{l}\text { No } \\
\text { thymoma }\end{array}$ \\
\hline Mean age (yr) & 49 & 50 \\
Men & 6 & 4 \\
Women & 9 & 11 \\
Type 2A & & \\
$\quad$ 2BA & 1 & 4 \\
$\quad$ 2B & 2 & 11 \\
4 & 3 & \\
4 & 3 &
\end{tabular}

2A $=$ mild myasthenia $; 2 B=$ moderate myasthenia $; 2 B A=$ mild myasthenia or remission evolved from $2 \mathrm{~B}$-type; $3=$ rapidly progressive severe myasthenia with spontaneous respiratory disturbance; $4=$ severe myasthenia evolved from 2B-type with respiratory disturbance (Oosterhuis, 1964).

RESULTS

The histological findings in the quadriceps femoris muscle and their relation to the presence of a thymoma are presented in Table II, which shows
TABLE II

PATHOLOGY OF THE QUADRICEPS MUSCLE IN 30 PATIENTS WITH MYASTHENIA GRAVIS

\begin{tabular}{lccr} 
Histology & $\begin{array}{c}\text { 15 patients } \\
\text { with } \\
\text { thymoma }\end{array}$ & $\begin{array}{l}\text { 15 patients } \\
\text { without } \\
\text { thymoma }\end{array}$ & $\begin{array}{c}\text { Total } \\
30\end{array}$ \\
\hline Normal & 6 & 11 & 17 \\
$\begin{array}{l}\text { Lymphorrhages only } \\
\text { Neurogenic changes and }\end{array}$ & 4 & 1 & 5 \\
$\begin{array}{l}\text { Nymphorrhages } \\
\text { Neurogenic changes only }\end{array}$ & 3 & 1 & 4 \\
Focal myositis and lymphorrhages & 2 & 2 & 2 \\
& 2 & - & 2
\end{tabular}

that nine out of 15 patients with a thymoma had muscular lymphorrhages, in contrast with two out of 15 patients without a thymoma $(P<0.05)$.

Antibodies to skeletal muscle were found in all 15 sera from patients with a thymoma, while only one out of 15 patients without a thymoma had the same antibodies $(P<0.001)$-(Table III).

\section{TABLE III}

CORRELATION BETWEEN THE OCCURRENCE OF THYMOMA, ANTIBODIES TO SKELETAL MUSCLE AND LYMPHORRHAGES IN PATIENTS WITH MYASTHENIA GRAVIS

\begin{tabular}{cccc} 
Thymoma & $\begin{array}{c}\text { Antibodies to } \\
\text { skeletal muscle }\end{array}$ & Lymphorrhages & No. \\
\hline+ & + & + & 9 \\
+ & + & - & 6 \\
+ & - & - & 0 \\
+ & - & + & 0 \\
- & + & - & 0 \\
- & + & - & 1 \\
- & - & 11 & 12 \\
15 & 16 & & 30
\end{tabular}

$+=$ present $;-=$ absent.

The same antibodies were determined in nine out of 11 sera from patients with lymphorrhages, in contrast with seven out of 19 patients without lymphorrhages $(P<0.05)$ - (Table III).

These data indicate a close correlation between thymoma, antimuscle-antibodies, and lymphorrhages in the muscle biopsy. The correlation between both methods by which antinuclear factors were investigated indicates the equivalence of these methods. Neurogenic changes are not related to the presence of a thymoma, nor to the presence of antimuscle antibodies or antinuclear factors. A slight, but not significant, relation was present between neurogenic changes and lymphorrhages (Table IV).

\section{DISCUSSION}

Our study has shown that patients with myasthenia gravis and a thymoma had lymphorrhages in quadriceps muscle biopsies (c.q. necropsies) more 
frequently than patients without a thymoma. No such relation applied to neurogenic muscular atrophy. The group of patients with thymomas showed a shorter average duration of illness and a more severe form of myasthenia. The nature of the material prohibited a study of the relation between the severity of myasthenia and the muscle pathology in patients without thymomas (Table I). This, however, would be required to establish with certainty whether it is the severity of the myasthenia or the presence of a thymoma that determines the presence of lymphocytic infiltrates.

A second uncertainty in our material is the difference in the mean duration of illness between the thymoma and the non-thymoma group. This raises the question whether the patients with a thymoma were in a more active immunological stage of their illness than the non-thymoma cases. Simpson (1960) discussed the possibility that lymphorrhages were a sign of allergic reaction, which could be found in the active stage of the illness, lasting five to seven years. From our own experience we can support this view, but this activity concerns primarily the neuromuscular transmission and not the immunological abnormalities.

From Table V it does not seem likely that the differences in duration account for the difference in the incidence of lymphorrhages, although this possibility cannot be definitely excluded. In a previous paper (Oosterhuis et al., 1967) we were not able to establish a relation between the duration of the disease and the presence of antibodies on $\bar{Z}$ the whole, whereas some antibodies showed an increasing frequency with age.

There is no indication that the supposed cellular immunity has a time-intensity relation that differs from that of the humoral immunity.

The absolute relation between thymoma and antiskeletal muscle antibodies, and the close relation between thymoma and muscle lymphorrhages suggests that the thymoma is the common factor in both. These correlations evoke several theoretical speculations.

1. One may suppose that the development of a thymoma causes small alterations in the thymic myoid cells (Mayer, 1888; Henry, 1966; FeltkampVroom, 1966; Strauss, Kemp, and Douglas, 1966a). These altered muscle antigens might evoke immunological reactions, cross-reacting with normal muscles. These reactions can be cellular (lymphorrhages) and/or humoral. It is unlikely that the antimuscle antibodies cause a neuromuscular block (McFarlin, Engel, and Strauss, 1966; Oosterhuis et al., 1967), but a neuromuscular blocking substance might be produced by the diseased thymus (Strauss Smith, Cage, Van der Geld, McFarlin, and Barlowa 1966b; Goldstein, 1966), or by the formation of the muscular antigen-antibody complex (Van de Geld et al., 1963).

2. On the other hand, it is possible that in the muscles of patients with myasthenia gravis, sligh alterations of the muscle tissue-that is, single fibre

\section{TABLE IV}

CORRELATION BETWEEN THE VARIABLES. CHI-SQUARE TEST

Thymoma Lymphorrhages $\begin{aligned} & \text { Neurogenic Anti-muscle A.N.F. rat A.N.F.human adrenal } \\ & \text { changes biopsy antibodies }\end{aligned}$

$\begin{array}{lll}\text { Thymona } & & \\ \text { Lymphorrhages biopsy } & <0.05 & \\ \text { Neurogenic changes biopsy } & \text { n.s. } & <0.20 \\ & & >0.10 \\ \text { Anti-muscle antibodies } & <0.001 & <0.05 \\ \text { A.N.F. rat liver } & <0.20 & \text { n.s. } \\ \text { A.N.F. human adrenal } & >0.10 & \\ & \text { n.s. } & \text { n.s. }\end{array}$

In Table: values of $P$ n.s. $=$ not significant $(P>0.2)$. changes biopsy antibodies liver 
atrophy-are produced by a persistent neuromuscular block.

These alterations might provoke the production of cross-reacting anti-skeletal muscle antibodies and muscular lymphorrhages.

The lymphorrhages around the thymic myoid cells might then impress as a lymphocellular thymitis, which may introduce the development of a thymoma. However, the alterations of muscle tissue in diseases other than myasthenia gravis do not produce antiskeletal muscle antibodies.

3. The serological and clinical overlap between myasthenia gravis and other idiopathic autoimmune diseases (Feltkamp, 1966; Oosterhuis et al., 1967) might be explained by supposing a primary disturbance of immunological tolerance. Thymic aberrations may be regarded as a cause of such a disturbance. Aberrations of the thymus are observed in patients with other autoimmune diseases.

In N.Z.B.-mice, with congenital autoimmune haemolytic anaemia, aberrations are located in the thymic epithelial cells (Vries and Hijmans, 1967). One may suppose that in patients with myasthenia gravis the aberrations are localized in the thymic myoid cells.

The second speculation is the less probable. The other two speculations might stimulate further experimental work to obtain information about the physiological function of myoid cells and their possible role in the aetiology and pathogenesis of myasthenia gravis.

The absolute relation between thymoma and anti-skeletal muscle antibodies and the close relation between thymoma and muscle lymphorrhages suggests that the thymoma is the common factor in both.

\section{SUMMARY}

In 30 patients with myasthenia gravis, an attempt was made to demonstrate a correlation between histological changes in the quadriceps muscle and the presence of a thymoma, or the presence of circulating antibodies against muscular tissue, or of antinuclear factors. Lymphocytic infiltrations were found more frequently in patients with a thymoma; no such relation was found between the presence of a thymoma and neurogenic changes. All patients with thymomas had antimuscle antibodies. A relation was established between lymphorrhages and antimuscle antibodies. It is probable that this relation is based on the linkage of both variables with thymomas.
Antinuclear factors had no relation to the histological changes. The correlation of thymomas, lymphocellular infiltrates in the muscles and humoral autoimmune reactivity to skeletal muscle is discussed.

\section{REFERENCES}

Engel, W. K., and McFarlin, D. E. (1966). Discussion on Fenichel's paper. Ann. N.Y. Acad. Sci., 135, 68-77.

Feltkamp, T. E. W. (1966). Idiopathic Autoimmune Diseases. A Study of Their Serological Relationship. Thesis. Drukkerif Aemstelstad Amsterdam.

_-_, and van Rossum, A. L. (1968). Antibodies to salivary duct cells, and other autoantibodies, in patients with Sjögren's syndrome and other idiopathic autoimmune diseases. Clin. exp. Immunol., 3, 1-16.

Feltkamp-Yroom, T. (1966). Myoid cells in human thymus. Lancet, $1,1320-1321$.

Fenichel, G. W. (1966). Muscle lesions in myasthenia gravis. Ann. N.Y. Acad. Sci., 135, 60-67.

$\longrightarrow$, and Shy, G. M. (1963). Muscle biopsy experience in myasthenia gravis. Arch. Neurol. (Chic.), 9, 237-243.

Genkins, G., Mendelow, H., Sobel, H. J., and Osserman, K. E. (1961). Myasthenia gravis: analysis of thirty-one consecutive postmortem examinations. In Myasthenia Gravis, ed. H. R. Viets, pp. 519-530. Thomas, Springfield, Illinois.

Goldstein, G. (1966). Thymitis and myasthenia gravis. Lancet, 2 , 1164-1167.

Henry, K. (1966). Mucin secretion and striated muscle in the human thymus. Ibid., 1, 183-185.

Link, R. (1903). Beitrage zur Kenntniss der Myasthenia gravis mit Befund von Zellherden in zahlreichen Muskeln. Dtsch. $Z$. Nervenheilk, 23, 114-124.

Mayer, S. (1888). Zur Lehre von der Schilddrüse und Thymus bei den Amphibien. Anat. Anz., 3, 97-103.

McFarlin, D. E., Engel, W. K., and Strauss, A. J. L. (1966). Does myasthenic serum bind to the neuromuscular junction? Ann. N.Y. Acad. Sci., 135, 656-663.

Mendelow, H. (1958). Pathology. In Myasthenia Gravis, ed. K. E. Osserman, pp. 10-43. Grune and Stratton, New York.

Oosterhuis, H J. G. H. (1963). Een Bijdrage Tot de Kliniek en de Pathophysiologie van de Myasthenia Gravis. Thesis. A. M. L. Koenders, Amsterdam.

- (1964). Studies in myasthenia gravis. Part I. A clinical study of 180 patients. J. Neurol. Sci., 1, 512-546.

Van der Geld, H. W. R., and Feltkamp, T. E. W. (1967). Studies in myasthenia gravis. Part II. The relation of some clinical and immunological data. Ibid., 4, 417-434.

Rowland, L. P., Hoefer, P. F. A., Aranow, H., and Houston-Merritt, H. (1956). Fatalities in myasthenia gravis. A review of 39 cases with 26 autopsies. Neurology (Minneap.), 6, 307-326.

Russell, D. S. (1953). Histological changes in the striped muscle in myasthenia gravis. J. Path. Bact., 65, 279-289.

Simpson, J. A. (1960). Myasthenia gravis, a new hypothesis. Scot. med. J., 5, 419-436.

Strauss, A. J. L., Kemp, P. G., and Douglas, S. D. (1966a). Myasthenia gravis. Lancet, 1, 772-773.

—, Smith, Ch. W., Cage, G. W., Yan der Geld, H. W. R., McFarlin, D. E., and Barlow, M. (1966b). Further studies on the specificity of presumed immune associations of myasthenia gravis and considerations of possible pathogenic implications. Ann. N.Y. Acad. Sci., 135, 557-579.

The, H. T., and Feltkamp, T. E. W. (1968). Conjugation of fluorescein isothiocyanate to antibodies. (In preparation).

Weigert, C. (1901). Pathologisch-anatomischer Beitrag zur Erbschen Krankheit (Myasthenia Gravis). Neurol. Zbl., 20, 597-601.

Van der Geld, H. W. R., Feltkamp, T. E. W., Loghem, J. J. V., Oosterhuis, H. J. G. H., and Biemond, A. (1963). Multiple antibody production in myasthenia gravis. Lancet, 2, 373-375.

Vries, M. J. de, and Hijmans, W. (1967). Pathological changes of thymic epithelial cells and autoimmune disease in NZB, NZW and NZB x NZW F, mice. Immunology, 12, 179. 